\title{
THE EFFECT OF AGING ON MICROSHEAR BOND STRENGTH OF RESIN CEMENT TO MONOLITHIC ZIRCONIA
}

\author{
Maged M. Mohamed Zohdy" and Ahmad Khaled Abo El Fadl**
}

\begin{abstract}
Purpose. Successful long-term bonding to zirconia ceramic remains a challenge, requiring special cements and treatments, which might negatively affect the ceramic.

The purpose of this study was to evaluate the durability of micro-shear bond strength between resin cement containing phosphate monomer and zirconia ceramic submitted to different surface treatments before and after aging.

Material and methods monolithic zirconia (Bruxzir Glidewell, California, USA) was selected as the substrate material. The ceramic surfaces, were either left untreated as-sintered (Group NT), silica coated with Rocatec soft system (3M/ESPE, USA) (Group CT), or treated with Alloy Primer (Kurary, Japan) (Group PR). They were bonded with a dual-cured resin cement; Panavia v5 (Kurary), using an adhesive system (Clearfil SE Bond). A micro-shear bond test was carried out to measure the bond strength of the resin cement to the zirconia surface. Samples were tested in a universal testing machine at a crosshead speed of $0.5 \mathrm{~mm} /$ minute before and after 90 days of water storage and 6000 thermal cycles (dwell time, 30 seconds). Statistical analysis was performed using a two-way ANOVA model, at $\mathrm{p}<0.05$. SEM analysis was performed to detect failure type.
\end{abstract}

Results. Mean microshear bond strength ranged from 14.39 to $21.59 \mathrm{MPa}$ after 3 days and from 5.64 to $20.42 \mathrm{MPa}$ after aging. Water storage and thermal cycling decreased bond strength significantly for NT and PR groups, while it had no significant effect on CT group. Early bond strength was highest with CT and PR groups with no significant difference between them, and they were both statistically significantly higher than NT group. SEM analysis showed an increase in interfacial adhesive failure after aging.

Conclusions. Within the limitations of this study, it was concluded that silica coating and application of a chemical primer produced higher bond strengths to resin cement than leaving zirconia untreated. Aging significantly reduced the bond strengths for the untreated and primed zirconia, while silica coated zirconia remained stable and was not affected.

* Lecturer at Fixed Prosthodontics Dept. Ain Shams University. Lecturer at Fixed Prosthodontics Dept. British University in Egypt.

** Lecturer at Fixed Prosthodontics Dept. Ain Shams University. Lecturer at Fixed Prosthodontics Dept. Misr International University. 


\section{INTRODUCTION}

Zirconia $(\mathrm{ZrO} 2)$ has recently been introduced as a promising metal-free core structure for fixed prostheses. ${ }^{1}$ The yttrium oxide-stabilized tetragonal zirconia polycrystal ( $3 \mathrm{Y}-\mathrm{TZP})$ is used in dentistry and it shows an outstanding mechanical, biocompatible, and aesthetic performance., ${ }^{2,3}$ Furthermore, the development of computer-aided design or computer-aided manufacturing (CAD/ CAM) technology has focused on the precise and consistent manufacturing of high strength and tough zirconia ceramics. ${ }^{3}$ As a completely bioinert material, zirconia provides completely unpolar surfaces with high corrosion resistance, thus lacking chemical adhesive potential or etchability. ${ }^{4}$

In addition (CAD/ CAM) technology has facilitated the design of frameworks and complete contour restorations as well as the processing of monolithic zirconia crowns and fixed dental prostheses (FDPs) ${ }^{5-7}$ Complete-contour monolithic zirconia restorations may provide adequate esthetics in the molar area. To enhance the translucency of zirconia, residual pores and impurities which create volumes of differing refractive indexes and lead to optical scattering on the surface and reduction of translucency must be reduced. ${ }^{8-15}$ Alumina, which is added to zirconia improve the mechanical properties and prevent low temperature degradation (LTD), is the most common impurity. ${ }^{16-22}$

All-ceramic restorations with various resinbased adhesive systems are increasingly required in clinical dentistry, since they provide excellent esthetic metal-free characteristics. However, the physical and bonding properties of ceramics are problematic. $^{23}$

Restorative ceramic materials can be roughly categorized into two groups, according to their sensitivity to hydrofluoric (HF) acids: acidsensitive and acid-resistant ${ }^{24,25}$. The bonding properties between resin-based adhesives and ceramics are mainly associated with the presence of silica on the surface that provides chemical compatibility mediated by silane-coupling agents ${ }^{26}$. The incorporated silica of acid-sensitive ceramics such as feldspathic, leucite, and lithium disilicate ceramics is well-exposed by HF acid gel to give increased surface roughness, which is then available for mechanical interlocking ${ }^{26,27,28}$. However, the use of such acid-sensitive ceramics is limited because of their brittle properties ${ }^{29,30,31}$.

Acid-resistant ceramics such as zirconia do not expose a silica layer on the surface, because there are no incorporated glass phases, and they cannot be chemically roughened, because of their stable microstructures ${ }^{26,27}$.

Laboratory or chairside air-abrasion with 110- and $30-\mu \mathrm{m}$ silica-coated aluminum particles (tribochemical silica coating) provide surface conditioning for acid-resistant ceramics. $25,26,32,33,34$ These air-abrasion systems allow the ceramic surface to be embedded by silica ${ }^{35}$ Silica-modified surfaces are chemically more reactive to the resin via silane coupling agents.

The performance of resin cements that contain 10-methacryloyloxydecyl dihydrogen phosphate (MDP) monomers as Panavia cements, has been studied previously. ${ }^{36,37,38,39,40}$ The results revealed high bonding durability of this cement to acidresistant ceramics because the phosphate ester group of MDP bonds directly to the metal oxides. ${ }^{36}$ It is observed in these studies that the combination of airabrasion with it did not yield stable bonds. . $13,36,37,38,39,41^{-1}$ However, controversial reports exist in the dental literature particularly after aging conditions..$^{34,42,43}$

In an attempt to improve bonding, the use of metal primers - following airborne particle abrasion - has recently been suggested to act as adhesion promoters $^{44}$. Metal primers are easy to apply and do not need complicated and expensive apparatus. Most metal primers are in liquid form, consisting of a monomer to polymerize in the solution. Initially, such metal primers were indicated for the repair of 
fractured metal-ceramic FPDs with metal exposure. However, subsequently, they were also indicated for conditioning reinforced ceramics including zirconia. Results with metal primers are not always favorable, chiefly because they reach a high bond strength under dry circumstances, but controversial reports emerge concerning their hydrolytic stability ${ }^{23,44}$.

Various adhesive monomers have been developed for chemical adhesion with the aim of achieving a durable bond between resin luting agents and base and noble metals. The adhesive functional monomers bond strongly to pure base metals and alloys because they have affinity for metal oxides that exist on the surface of metals such as chromium, tin, titanium, and copper ${ }^{45,46}$.

Establishing a strong bond with zirconia is only one part of the problem. A more crucial aspect would be maintaining this bond under the influence of fatigue conditions, in presence of saliva, and temperature changes for a clinically acceptable time. Several studies investigated the influence of accelerated artificial aging using water storage, thermocycling, or fatigue and reduction in zirconia resin bond strength was observed ${ }^{47}$. On the contrary, there is also evidence that still supports the use of MDP monomer on particle-abraded zirconia as a method for establishing a durable zirconia resin bond ${ }^{48}$. Unfortunately, these studies were preformed under controlled laboratory conditions and there is not yet clinical evidence that confirms such findings.

Therefore, the objectives of this study were to evaluate the durability of bond strength between resin cement containing phosphate monomer and zirconia ceramic submitted to different surface treatments before and after aging.

\section{MATERIALS AND METHODS}

Eighteen 14 x 14 x 1 mm machinable monolithic zirconia ceramic plates (Bruxzir Glidewell, California, USA ) were sliced from their respective blocks by using a low speed diamond saw (Buehler-
Isomet LakeBulff, IL, USA) After slicing, the zirconia plates were cleaned ultasonically in distilled water and then sintered in a ceramic sintering furnace (InFire HTC, Sirona), for 7 hours at 1550oc.

Zirconia specimens were assigned to the following groups depending on the surface treatment method:

Group NT: No surface treatment applied. Zirconia surface was left as-sintered.

Group CT: silica coating using Rocatec soft with particle size of $30 \mu \mathrm{m}$ were used (3M/ESPE, USA). Particles were ejected at a pressure of 2.8 bars for a period of 15 seconds and at a distance of $10 \mathrm{~mm}$ Silane coupling agent (RelyX Ceramic Primer, 3M/ ESPE) was then applied and left to dry for one minute.

Group PR: A commercial primer (Alloy Primer, Kurary) containing adhesive monomers effective for base metals was used in this study. The surface of the zirconia specimens was coated with a thin single layer of the primer using a new, clean, fine brush. The primer was allowed to dry and react for 3 min and then gently air-blasted dry with an oil-free air stream

One cement was used for all specimens; PanaviaV5 adhesive resin cement, which depends on the presence of 10-MDP monomers. The materials utilized and their characteristics are listed in table1.

The adhesive bonding resin (Clearfil SE) was applied to the zirconia surface under test and lightcured at for 20 seconds. Prior to the light-curing step, plastic tubes $0.75 \mathrm{~mm}$ in diameter and $0.5-\mathrm{mm}$ thick were placed on the uncured adhesive surfaces of each plate. These surfaces were then polymerized to stabilize the plastic tube on the ceramic surface. Because the plastic cylinder was bonded tightly to the ceramic surface, no flash of resin composite extended onto the ceramic beyond the base of the cylinder. 
TABLE (1) List of the main materials used in the study showing their composition

\begin{tabular}{|c|c|c|c|}
\hline Material & Type & Composition & Manufacturer \\
\hline Panavia v5 & $\begin{array}{l}\text { Dual polym-erizing } \\
\text { resin luting agent }\end{array}$ & $\begin{array}{l}\text { 1. Bisphenol A Diglycidyl-methacrylatw } \\
\text { 2. Triethylene glycol dimethacrylate } \\
\text { 3. Silanated barium Glass } \\
\text { 4. Silica } \\
\text { 5. Aluminum oxide } \\
\text { 6. Aromatic dimethacrylate } \\
\text { 7. Aliphatic dimethacrylate } \\
\text { 8. Camphorquinone } \\
\text { 9. Accelerators } \\
\text { 10. Pigaments }\end{array}$ & $\begin{array}{l}\text { Kurary Medical, Inc } \\
\text { Okayama, Japan }\end{array}$ \\
\hline $\begin{array}{c}\text { Clearafil } \\
\text { ceramic } \\
\text { primer plus }\end{array}$ & $\begin{array}{l}\text { Universal } \\
\text { Primer }\end{array}$ & $\begin{array}{l}\text { 1. Ethanol } \\
\text { 2. Silane } \\
\text { 3. MDP }\end{array}$ & $\begin{array}{l}\text { Kuraray, Osaka, } \\
\text { Japan }\end{array}$ \\
\hline Alloy Primer & Liquid primer & $\begin{array}{l}\text { MDP (10-methacryloxydecyldihydrogenphosphate) } \\
\text { 6-(4-vinylbenzyl-n-propyl)amino-1,3,5-triazine-2,4- } \\
\text { dithione (VTD), acetone }\end{array}$ & $\begin{array}{l}\text { Kurary Medical, Inc } \\
\text { Okayama, Japan }\end{array}$ \\
\hline
\end{tabular}

After curing, Panavia V5 cement was placed into the tube iris and cured for 40 seconds. The plates were stored at room temperature $\left(23^{\circ} \mathrm{C}\right)$ for 1 hour prior to removal of the plastic tubing. In this manner, a small cylinder of resin composite 0.75 $\mathrm{mm}$ in diameter and $0.5 \mathrm{~mm}$ in height was bonded to the ceramic surface. Twenty specimens were created in each group. Before the test, all resin cylinders were checked under an optical microscope (20x). The cylinders that showed no apparent interfacial defects or bubble inclusion and no leaking of composite core were tested.

Each bonding group was divided into two subgroups of 10 resin specimens each; one subgroup to be tested for micro-shear bond strength before artificial aging, and the other to be tested after artificial aging.

In the first subgroup specimens were stored in distilled water at room temperature for 3 days without thermal cycling (TC), while in the second subgroup, they were stored for 90 days with additional 6000 thermal cycles between 5 and $55^{\circ} \mathrm{C}$ (dwell time $30 \mathrm{~s}$ and transfer time $7 \mathrm{~s}$ ). Following the different storage times, the micro-shear bond strength test was performed.

Each ceramic plate was attached to the testing device. A wire loop prepared from an orthodontic stainless steel ligature wire $(0.2 \mathrm{~mm}$ diameter $)$ was wrapped around the bonded assembly so that it was as close as possible to the base of the resin composite. The resin-ceramic interface for the test, the wire loop, and center of the load cell were aligned as straight as possible to ensure the desired orientation in the shear test force. A shear load was applied via a universal testing machine (Lloyd instrument, UK) at a crosshead speed of $0.5 \mathrm{~mm} /$ min until failure occurred (Fig 1).

Interfacial shear strength was calculated by dividing the maximum load recorded on failure by the circular bonding area in square millimeters and expressed in MPa. Specimens that failed prematurely during handling were assigned zero strength values and were included in the statistical analysis. Statistical analysis was performed using the SPSS statistical package (SPSS 11.5, SPSS, Chicago, IL). The means of each group were analyzed by two-way ANOVA with micro-shear 


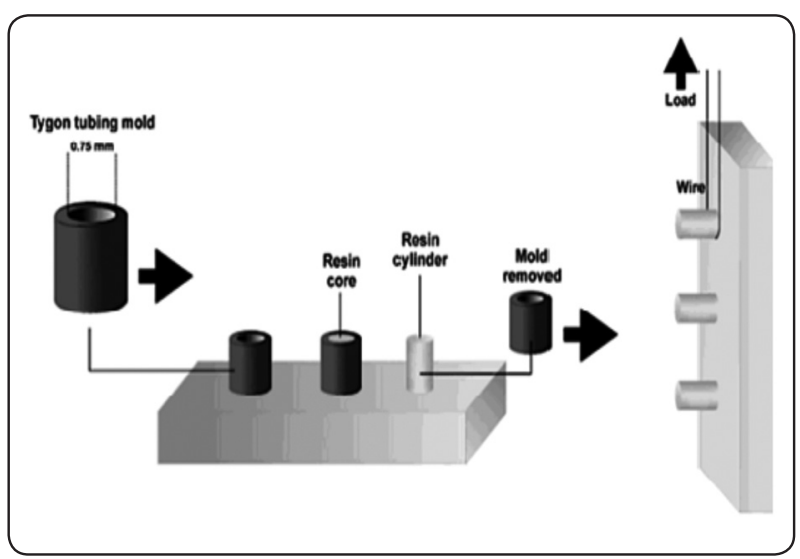

Fig. (1) Schematic illustration of the process of bonding and testing.

bond strength as the dependent variable and surface treatment and storage condition of specimens as independent factors. Tukey's compromise test with $\mathrm{p}<0.05$ was used to establish significance.

Selected ceramic surfaces were analyzed using scanning electron microscopy (SEM). Failure type was classified into interfacial failure across the zirconia-resin interface resulting in exposure of the zirconia surface or cohesive failure in the ceramic material or the adhesive resin

\section{RESULTS}

The shear bond strength mean values for the various groups are shown in Table 2. Statistically significant differences between the groups and between the storage conditions are indicated in the same table $(\mathrm{p}<0.05)$. The ceramic surface pretreatment and the storage period, significantly affected the micro-shear bond strength to zirconia ceramic.

For the 'as-sintered' specimens (NT group), many specimens demonstrated spontaneous premature failure during testing which was responsible for the low bond strength value and the high standard deviation observed. The specimens with surface treatments exhibited higher bond strengths and none failed spontaneously during testing.

The highest bond strength values were seen for CT group (21.59 MPa), and PR group
(21.13 MPa) under pre-aging conditions, and there was no statistical significant difference between them. They were both better than the NT group (14.39 MPa) with significant difference.

Water storage resulted in significant reduction in the initially established zirconia resin bond strength. After 6 months of water aging, bond strength values dramatically decreased in NT group. Bond strengths of RT group had no significant difference after water storage . For the PR group, there was a significant decrease in bond strength after aging.

TABLE (2) Mean micro-shear bond strength of different surface treatment groups in preaging and post-aging conditions, showing standard deviations and statistical significance

\begin{tabular}{|l|c|c|c|c|c|c|}
\hline & \multicolumn{2}{|c|}{$\begin{array}{c}\text { Pre-aging Micro- } \\
\text { shear bond strength } \\
\text { (MPa) }\end{array}$} & \multicolumn{3}{c|}{$\begin{array}{c}\text { Post-aging Micro- } \\
\text { shear bond strength } \\
\text { (MPa) }\end{array}$} \\
\hline Treatment & Mean & Sd & Sig & Mean & Sd & Sig \\
\hline NT & 14.39 & 2.37 & B & 5.64 & 3.19 & C \\
\hline CT & 21.59 & 1.66 & A & 20.42 & 2.26 & A \\
\hline PR & 21.13 & 1.47 & A & 15.81 & 1.72 & B \\
\hline
\end{tabular}

Sig: Statistical significance. Values with different letters indicate significant difference.

SEM examination of the tested specimens (fig. $2,3,4)$ revealed an interfacial failure type for the 'as-sintered' specimens (NT) as the entire surface of zirconia was exposed indicating weak bond strength, and completely adhesive type of failure. For the silica coated samples (RT), the failure mode was completely cohesive after 3 days and mostly cohesive (98\%) after 150 days, whereas the specimens treated with zirconia primer (PR), showed apredominantly cohesive failure mode after 3 days, but a nearly $100 \%$ adhesive failure mode after 150 days. 


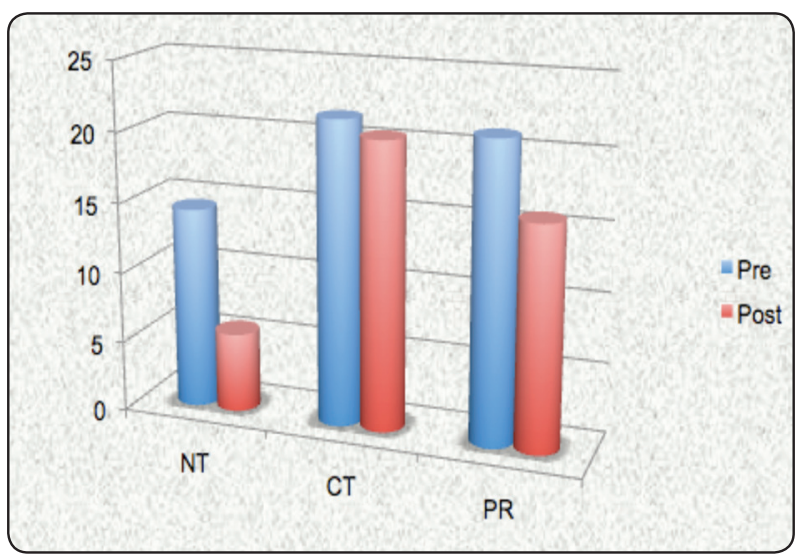

Fig. (2) Column chart showing the mean micro-shear bond strengths of the different tested groups.

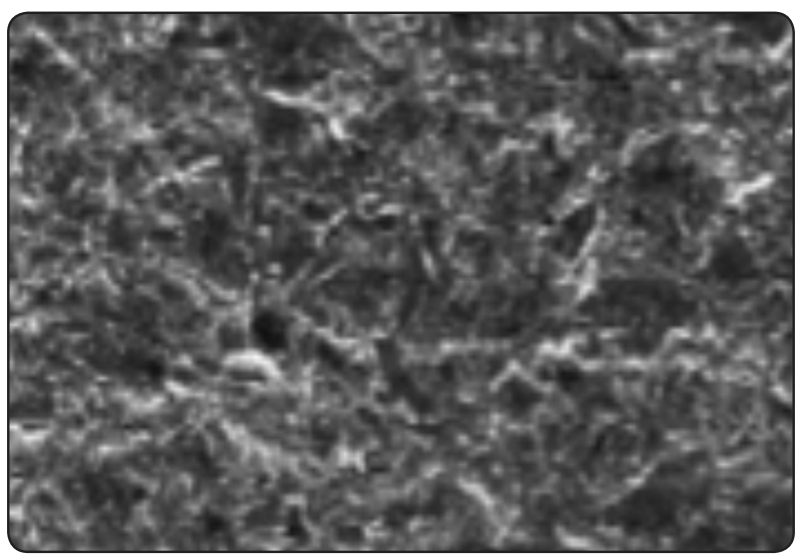

Fig. (4) SEM of NT zirconia showing completely adhesive failure

\section{DISCUSSION}

The zirconium oxide stabilized with an addition of yttrium oxide give a high strength ceramic with a better fracture toughness than that of an aluminum oxide ceramic. Its material properties have made it suitable to use in orthopedic clinics, and these advantages have also made it interesting as a restorative material in the dental clinic. The advantages of the material in combination with the development of new processing techniques have made zirconia an interesting material in the production of crowns and bridges.

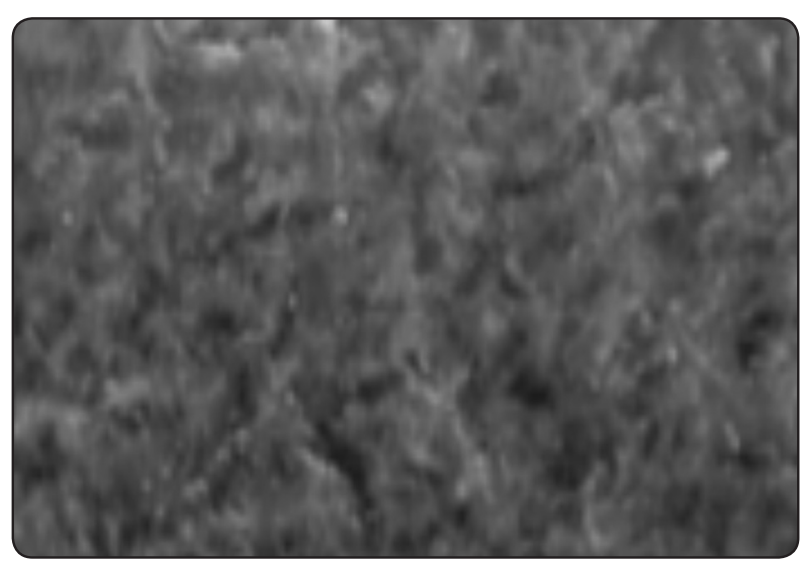

Fig. (3) SEM of CT zirconia showing completely cohesive failure

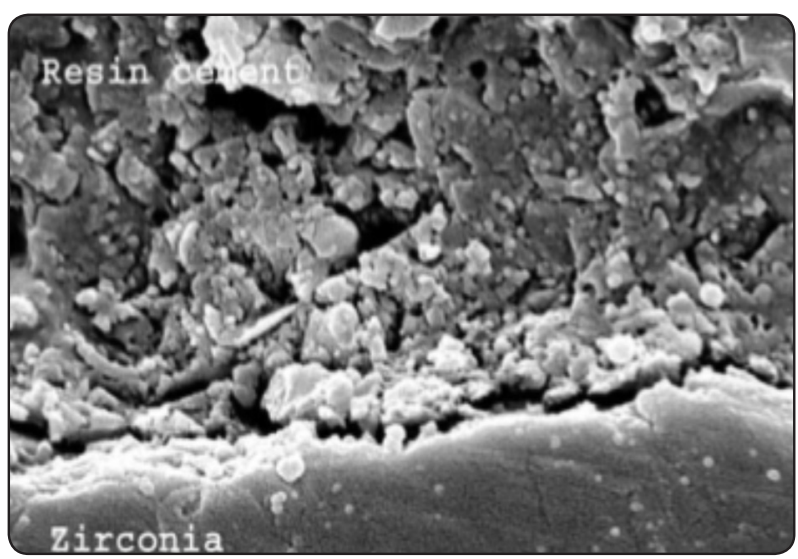

Fig. (5) SEM of PR zirconia surface after aging showing microgaps due to bond hydrolysis

Due to optical opacity of these materials, zirconia is used as substructure material that is veneered with feldspathic ceramics. In clinical application, limited number of studies reported seldom zirconia substructure fractures but chipping of the veneer is described to be the most frequent occurrence that reduces the success rate of zirconia FPDs ${ }^{49,52}$. In order to overcome this problem, translucent toothcolored zirconia (monolithic zirconia) which enables the fabrication of restorations without using veneering ceramic has been developed. Advantages of monolithic zirconia restorations include limited amounts of defects due to fabrication of 
the restoration from presintered homogeneous blocks with Computer Aided Design/Computer Aided Manufacturing (CAD/CAM) technique and reduced production time/cost. Also, permitting a minimal material thickness of $0.5 \mathrm{~mm}$ due to high mechanical strength contributes to the preservation of tooth substance and enables the use of ceramic restoration in case of limited interocclusal space ${ }^{53}$.

It has been previously demonstrated that the bond strength of resin-based materials to acid-resistant ceramics, such as zirconia, is neither durable nor stable ${ }^{36,43,54}$, due in-part to the non-reactive nature of its surface. Such an inferior bonding performance thus poses a formidable challenge to the clinicians, especially when bonding non-retentive zirconia FPDs. Studies have investigated multiple treatment techniques, ranging from physical roughening (to increase the bonding surface area) to surface coating and application of reactive monomers (to promote chemical attachment to the polymer adhesive).

It has been suggested that $10-13 \mathrm{MPa}$ is the minimum strength needed for clinical bonding ${ }^{55}$.

The results of the present study show that the bond strength was influenced by both, the different surface conditioning methods and the storage conditions.

No treated zirconium oxide ceramic is a relatively inert substrate with low surface energy and wettability. The low bond strength observed in this study for the 'as-sintered' specimens has also been reported in other studies using different combinations of surface treatment and bonding resincomposite. Such findings indicate that establishing a strong chemical bond with zirconia is a difficult procedure when not combined with any surface pre-treatment ${ }^{25,32}$, even though all specimens were bonded using a MDP-containing resin (Panavia). No beneficial effect could be attributed to the phosphate monomer alone. Supporting this conclusion is the observation that when the same bonding resincomposite was used on silica coated specimens, a significant increase in bond strength was observed.
Such findings directly reflect the need to establish mechanical retention to gain any benefit from the MDP resin-composite. These results were further clarified by subjecting the specimens to artificial aging $^{27,56}$.

Surface abrasion with a tribochemical silicacoated alumina has been shown to be an effective bonding promoter treatment for zirconia by physically roughening the surface while also leaving behind both physically and chemically bound silica ${ }^{57}$. The bound silica particles serve as reactive sites for conventional organo-silane monomer primers,

The silane molecules react with water forming silanol groups $(-\mathrm{Si}-\mathrm{OH})$ from methacryloxy groups, and silanol groups react with the silica deposited on the material surface to form a siloxane network ($\mathrm{Si}-\mathrm{O}-\mathrm{Si}-\mathrm{O}-$ ). As for the monomeric ends of silane, they react with the methacrylate groups of the resin material. Thus, the bonding process between a silica-coated ceramic surface and resin cement occurs through a combination of micromechanical and chemical processes ${ }^{58}$. This explains the high bond strength obtained in CT group.

Metal primers are easy to apply, and saddled with other advantages of good price-performance and no need for proprietary apparatus. They are usually supplied as single-liquid primers composed of a polymerizable monomer in a suitable solvent. These products are often called primers despite the fact that they are also coupling agents. Typically, these systems are considered as simplified chairside applications. However, a careful study of the manufacturer's instructions would reveal that prior to metal primer application, $\mathrm{Al} 2 \mathrm{O} 3$ airborne particle abrasion is also required. Therefore, bond strength is not derived purely from the metal primer, but that the need for airborne particle abrasion remains. Although these primers deliver high bond strength results at dry conditions, a reduction of $30-90 \%$ after aging has been noted ${ }^{23}$. 
The application of MDP-containing cement with its adhesive potential to densely sintered zirconia may depend on the presence of a passive coating of zirconium oxide on the ceramic surface. Chemical reactions involving the hydroxyl groups of the layer and the phosphate ester monomers of the MDP may occur at the interfacial level ${ }^{31,59}$. Moreover, the functional monomer has been rated as relatively hydrolysis stable, due to the presence of a long carbonyl chain. Conventional silanes are not as effective on zirconia as on silica-based ceramics ${ }^{23}$. Nonetheless, the silane molecule (3-MPS) mixed with $10-\mathrm{MDP}$ in the coupling solution may have promoted the bonding mechanism, improving surface wettability and forming cross-linkages with methacrylate groups as well as siloxane bonds with the $\mathrm{OH}$ - groups of the ceramic substrate ${ }^{23}$. Such a reaction may be promoted and sustained by the acidity of the substrate treated with the coupling solution. A relatively strong poly-molecular layer may be responsible of the ceramic-resin cement bond

Adhesive functional monomers bond strongly to the oxides of pure base metals and alloys ${ }^{46}$. When zirconia ceramic was primed with Alloy Primer, the shear bond strength of the resin luting agent was significantly improved compared with the untreated group before aging. The hydrophilic nature of MDP, 4-META, and in commercial primers plays an important role in the bonding of resin luting agent to zirconia. Previous studies have shown that 4-META and MDP acted as coupling agents, similar to silane coupling agents, ${ }^{23}$. Adhesive monomers may bond chemically to the zirconia surface, due to reaction between the hydroxyl groups on zirconia ceramic surface and the carboxyl groups in 4-MET (hydrolyzed 4-META) or hydrogen groups in MDP, similar to the surface reaction between silane coupling agents and silica-based ceramics.

Various studies used artificial aging by longterm water storage and thermal cycling to include clinically relevant parameters to identify superior bonding methods and materials. ${ }^{33,36,37,48,57.60}$ This test method, allowed evaluation of the expected longterm performance of the bond under the influence of water. Immersion of the specimens under water exposes more surface area of the bonding interface which tests more effectively the hydrolytic influence of water on the established bond. Water storage has the tendency to reduce bond strength values especially in combination with polycrystalline ceramics such as alumina and zirconia where only weak chemical bonds could be established using organophosphate-based monomers, such as MDP ${ }^{23,59}$.

After 6 months of storage, statistically significant decline in bond strength was registered when luting Panavia to either untreated or primed zirconia surfaces. In contrast, when Panavia was luted to silica-coated zirconia surfaces, no significant bond strength variability was evidenced after 6-month of water exposure. The functional monomer 10-MDP (10-methacryloxydecyl-dihydrogen-phosphate) has been rated as relatively hydrolytic stable ${ }^{61}$, due to the presence of a long carbonyl chain ${ }^{34,62}$. The results of this investigation, similarly to those of other in vitro tests, suggest that applying a tribochemical system combined with a phosphate monomer-containing luting agent could be a recommendable option for ensuring the long-term success of bonding to zirconia, as it enhances the acidic functionalmonomers capability of chemically reacting with the substrate $^{31,59,63}$. Adhesive failure mode significantly increased in untreated and primed samples over the storage period. Water storage might dilute soluble monomers to an extent that could lead to the entrapment of water droplets within the adhesive primer ${ }^{64}$, causing a decrease in bond strength and retention at the resin-cement/zirconia interface.

Under clinical conditions where fatigue is the dominant factor contributing to failure, bond reduction is even more expected and could lead to marginal deterioration and debonding of zirconia resin bonded restorations ${ }^{65}$. Under such conditions, selection of the bonding mechanism should focus equally on long-term bond strength ability as well as the initial high bond strength value ${ }^{31}$. 
Analysis of the broken specimens revealed an interfacial failure indicating that the zirconia-resin interface was the weakest link in the structure. Such finding could be related to two important factors. The first factor is the hydrolytic effect of water on adhesive joints.

The second factor is the water inhibition phenomenon that could lead to thickening of the cement layer leading to disruption of the established bond. Relatively warm water is absorbed in resincomposite cements and warm treatment also leads to some post-polymerization of the MDP cement. On the other hand, in silane-aided bonding film, the bonds can re-arrange dynamically, without ultimately weakening the bonding itself ${ }^{56}$.

A possible phenomenon of water entrapment may have hampered the bond potential of resin cement $^{31,66}$. It has been proven that water, owing to its small molecular size and high molar concentration, can penetrate into nanometer-size free-volume spaces between polymer chains or cluster around functional groups that are capable of hydrogen bonding resulting in a decrease in thermal stability and polymer plasticization ${ }^{31}$. Water sorption may have determined cement hydrothermal degradation during aging

It should be mentioned that chemical surface treatment with primer only would not produce a long-term durable bond between zirconia ceramics and resin luting agents.

\section{CONCLUSIONS}

Within the limitations of this study, the following conclusions were drawn:

1. The use of an adhesive phosphate monomercontaining cement produced clinically acceptable early micro-shear bond strengths values for all tested groups.

2. Tribochemical silica coating and application of a primer improved the bond strength significantly, in relation to the as-sintered zirconia.
3. Artificial aging played an important role in resin-cement/zirconia-ceramic bonds degradation. Chairside silica coating followed by silanization showed durable bond strength of the resin cement zirconia ceramic, while the primed zirconia showed a significant decrease after aging, and the as-sintered untreated zirconia showed the largest decrease in bond strength.

\section{REFERENCES}

1. Denry I, Kelly JR. State of the art of zirconia for dental applications. Dent Mater 2008;24:299-307.

2. Raigrodski AJ. Contemporary materials and technologies for all-ceramic fixed partial dentures: A review of the literature. J Prosthet Dent 2004;92:557-562.

3. Tinschert J, Natt G, Hassenpflug S, Spiekermann H. Status of current CAD/CAM technology in dental medicine. Int $\mathrm{J}$ Comput Dent 2004; 7:25-45.

4. Hao L, Lawrence J, Chian KS. Osteoblast cell adhesion on a laser modified zirconia based bioceramics. J Mater Sci: Mater Med 2005;16:719-726.

5. Kohorst P, Junghanns J, Dittmer MP, Borchers L, Stiesch M. Different CAD/CAM-processing routes for zirconia restorations: influence on fitting accuracy. Clin Oral Investig 2011;15:527-36.

6. Guess PC, Bonfante EA, Silva NR, Coelho PG, Thompson VP. Effect of core design and veneering technique on damage and reliability of Y-TZP-supported crowns. Dent Mater 2013;29:307-16.

7. Mehra M, Vahidi F. Complete mouth implant rehabilitation with a zirconia ceramic system: a clinical report. J Prosthet Dent 2014;112:1-4

8. Peelen JGJ, Metselaar R. Light scattering by pores in polycrystalline materials: Transmission properties of alumina. J Appl Phys 1974;45:216-20.

9. Apetz R, Bruggen MPB. Transparent alumina: A LightScattering Model. J Am Ceram Soc 2003:480-6.

10. Yamashita I, Nagayama H, Tsukuma K. Transmission properties of translucent Polycrystalline Alumina. J Am Ceram Soc 2008;91:2611-6.

11. Tsukuma K, Yamashita I. Transparent 8 mol\% Y2O3eZrO2 (8Y) ceramics. J Am Ceram Soc 2008;91:813-8. 
12. Yamashita I, Tsukuma K. Light scattering by residual pores in transparent zirconia ceramics. J Ceram Soc Jpn 2011:133-5.

13. Klimke J, Trunec M, Krell A. Transparent tetragonal yttriastabilized zirconia ceramics: influence of scattering caused by birefringence. J Am Ceram Soc 2011:1850-8.

14. Zhang Y. Making yttria-stabilized tetragonal zirconia translucent. Dent Mater 2014;30:1195-203.

15. Denry I, Kelly JR. Emerging ceramic-based materials for dentistry. J Dent Res 2014;93:1235-42.

16. Flinn BD, deGroot DA, Mancl LA, Raigrodski AJ. Accelerated aging characteristics of three yttria-stabilized tetragonal zirconia polycrystalline dental materials. J Prosthet Dent 2012;108:223-30.

17. De Aza AH, Chevalier J, Fantozzi G, Schehl M, Torrecillas R. Crack growth resistance of alumina, zirconia and zirconia toughened alumina ceramics for joint prostheses. Biomaterials 2002;23:937-45.

18. Deville S, Chevalier J, Fantozzi G, Bartolome GF, Requena J, Moya JS, Torrecillas R, Diaz LA. Low-temperature ageing of zirconia-toughened alumina ceramics and its implication in biomedical implants. J Eur Ceram Soc 2003;23:2975-82.

19. Tsubakino H. Isothermal tetragonal-to-monoclinic phase transformation in a

20. zirconiaeyttria system. Mater Trans 2005;46:1443-51.

21. Nogiwa-Valdez AA, Rainforth WM, Zeng P, Ross IM. Deceleration of hydrothermal degradation of 3Y-TZP by alumina and lanthana co-doping. Acta Biomater 2013;9:6226-35.

22. Ban S, Sata H, Suehiro Y, Nakanishi H, Nawa M. Biaxial flexure strength and low temperature degradation of Ce-TZP/A12O3 nanocomposite and Y-TZP as dental restoratives. J Biomed Mater Res B Appl Biomater 2008; $87: 492-8$.

23. Maria CL, Susanne SS, Patrick A, Marc J, HW Anselm W. Low-temperature degradation of a Y-TZP dental ceramic. Acta Biomater 2011;7:858-65.

24. Yoshida K, Tsuo Y, Atsuta M. Bonding of dual-cured resin cement to zirconia ceramic using phosphate acid ester monomer and zirconate coupler. J Biomed Mater Res B Appl Biomater 2006; 77: 28-33.

25. Valandro LF, Leite FPP, Scotti R, Bottino MA, Neisser MP. Effect of ceramic surface treatment on the microtensile bond strength between a resin cement and an aluminabased ceramic. J Adhes Dent 2004; 6:327-332.
26. Bottino MA, Valandro LF, Scotti R, Buso L. Effect of surface treatments on the resin bond to zirconium-based ceramic. Int J Prosthodont 2005;18:60-65.

27. O” zcan M, Vallittu PK. Effect of surface conditioning methods on the bond strength of luting cement to ceramics. Dent Mater 2003;19:725-731.38.

28. Della Bona A, Anusavice KJ, Shen C. Microtensile strength of composite bonded to hot-pressed ceramics. J Adhes Dent 2000;2:305-13.

29. Della Bona A, Anusavice KJ. Microstructure, composition, and etching topography of dental ceramics. Int $\mathrm{J}$ Prosthodont 2000; 15:159-167.

30. Scotti R, Catapano S, D'Elia A. A clinical evaluation of InCeram crowns. Int J Prosthodont 1995; 8:320-323.

31. Oden A, Andersson M, Krystak-Ondracek I, Magnusson D. Five-year clinical evaluation of Procera AllCeram crown. J Prosthet Dent 1998; 80:450-456.

32. A.J. Raigrodski, G.J. Chiche, N. Potiket, J.L. Hochstedler, S.E. Mohamed, S. Billiot,D.E. Mercante, J. Prosthet. Dent. 96 (2006) 237-244

33. I. Sailer, A. Fehér, F. Filser, L.J. Gauckler, H. Lüthy, C.H. Hämmerle, Int. J.Prosthodont. 20 (2007) 383-388.

34. D. Edelhoff, B. Florian, W. Florian, C. Johnen, Quintessence Int. 39 (2008) 459-471.

35. J. Schmitt, S. Holst, M. Wichmann, S. Reich, M. Gollner, J. Hamel, Int. J. Prosthodont. 22 (2009) 597-603.

36. R. Sadid-Zadeh, P.R. Liu, R. Aponte-Wesson, S.J. O’Neal, J. Adv. Prosthodont. 5 (2013) 209-217.

37. Kern M, Wegner SM. Bonding to zirconia ceramic: Adhesion methods and their durability. Dent Mater 1998;14:64-71.

38. O” zcan M, Alkumru H, Gemalmaz D. The effect of surface treatment on the shear bond strength of luting cement to a glass-infiltrated alumina ceramic. Int J Prosthodont 2001;14: 335-339.

39. Kern M, Thompson VP. Bonding to glass infiltrated alumina ceramic: Adhesive methods and their durability. J Prosthet Dent 1995;73:240-249.

40. Valandro LF, O” zcan M, Bottino MC, Bottino MA, Scotti $\mathrm{R}$, Della Bona A. Bond strength of a resin cement to highalumina and zirconia-reinforced ceramics: The effect of surface conditioning. J Adhes Dent 2006;8:175-181.

41. Sun R, Suansuwan N, Kilpaltrick N, Swain M. Characterisation of tribochemical assisted bonding 
of composite resin to porcelain and metal. J Dent 2000;28:441-445.

42. Wegner SM, Kern M. Long-term resin bond strength to zirconia ceramic. J Adhes Dent 2000;2:139-147.

43. Hummel M, Kern M. Durability of the resin bond strength to the alumina ceramic Procera. Dent Mater 2004;20:498508.

44. Luthy H, Loeffel O, Hammerle CHF. Effect of thermocycling on bond strength of luting cements to zirconia ceramic. Dent Mater 2006;22:195-200.

45. Wegner SM, Gerdes W, Kern M. Effect of different artificial aging conditions on ceramic-composite bond strength. Int J Prosthodont 2002;15:267-272.

46. Zhang Y, Pajares A, Lawn BR. Fatigue and damage tolerance of Y-TZP ceramics in layered biomechanical systems. J Biomed Mater Res B: Appl Biomater 2004;71:166-171.

47. Friederich R, Kern M. Resin bond strength to densely sintered alumina ceramic. Int J Prosthodont 2002;15:333338.

48. Amaral R, O* zcan M, Bottino MA, Valandro LF. Microtensile bond strength of a resin cement to glass infiltered zirconia-reinforced ceramic: The effect of surface conditioning. Dent Mater 2006;22:283-290.

49. Valandro LF, O” zcan M, Amaral R, Leite FPP, Bottino MA. Microtensile bond strength of a resin cement to silica coated and silanized In-Ceram zirconia before and after aging. Int J Prosthodont. 2007;20:70-72.

50. Yoshida K, Atsuta M. Effects of adhesive primers for noble metals on shear bond strengths of resin cements. J Dent 1997; 25: 53-58.

51. Ohno H, Araki Y, Sagara M. The adhesion mechanism of dental adhesive resin to the alloy: Relationship between Co-Cr alloy surface structure analyzed by ESCA and bonding strength of adhesive resin. Dent Mater J 1986; 5: 46-65.

52. Kojima K, Kadoma Y, Yamauchi J. Study on adhesive primer to dental metal used for composite type resin cement. J J Dent Mater 1997; 16: 316-321.

53. Wegner SM, Kern M. Long-term resin bond strength to zirconia ceramic. J Esthet Restor Dent 2004;16:327-8.

54. Quaas AC, Yang B, Kern M. Panavia F 2.0 bonding to contaminated zirconia ceramic after different cleaning procedures. Dent Mater 2007;23:506-12.
55. Dérand P, Dérand T. Bond strength of luting cements to zirconium oxide ceramics. Int J Prosthodont 2000; 13: 131-135.

56. Thurmond J, Barkmeier W, Wildweding M. Effect of porcelain surface treatments on bond strength of composite resin bonded to porcelain. J Prosthet Dent 1994; 72: 355359.

57. Matinlinna JP, Heikkinen T, Ozcan M, Lassila LV, Vallittu PK. Evaluation of resin adhesion to zirconia ceramic using some organosilanes. Dent Mater 2006;22:824-31.

58. Blatz MB, Sadan A, Kern M. Resin-ceramic bonding: a review of the literature. J Prosthet Dent 2003;89(2):26874.

59. Özcan M, Matinlinna JP, Vallittu PK, Huysmans MC. Effect of drying time of 3-methacryloxypropyl-trimethoxysilane on the shear bond strength of a composite resin to silicacoated base/noble alloys. Dent Mater 2004; 20: 586-590.

60. Wolfart M, Lehmann F, Wolfart S, Kern M. Durability of the resin bond strength to zirconia ceramic after using different surface conditioning methods. Dent Mater 2007;23:45-50.

61. Sadoun M, Asmussen E. Bonding of resin cements to an aluminous ceramic: a new surface treatment. Dent Mater 1994;10:185-9.

62. Valandro LF, Della Bona A, Bottino MA, Neisser MP. The effect of ceramic surface treatment on bonding to densely sintered alumina ceramic. J Prosthet Dent 2005;93:253-9.

63. Palacios RP, Johnson GH, Phillips KM, Raigrodski AJ. Retention of zirconium oxide ceramic crowns with three types of cement. J Prosthet Dent 2006;96:104-14.

64. Burke FJ, Flemming GI, Nathanson D, Marquis PM. Are adhesive technologies needed to support ceramics? An assessment of the current evidence. J Aesthet Dent 2002;4:7-22.

65. Toledano M, Osorio R, Osorio E, Aguilera FS, Yamauti M, Pashley DH, et al. Durability of resin-dentin bonds: effects of direct/indirect exposure and storage media. Dent Mater 2007;23:885-92.

66. Simon JF, Gartrell RG, Grogono A. Improved retention of acid-etched fixed partial dentures: a longitudinal study. J Prosthet Dent 1992;68:611-5.

67. Lüty H, Loeffel O,Hammerle CHF. Effect of thermocycling on bond strength of luting cements to zirconia ceramic. Dent Mater 2006;22:195-200. 